Short Communication

\title{
Neuronal surface antibody-mediated encephalopathy as manifestation of chronic graft-versus-host disease after allogeneic hematopoietic stem cell transplantation
}

\author{
Michelle Pirotte $^{\mathrm{a}, 1}$, Florence Forte ${ }^{\mathrm{b}, 1}$, Laurence Lutteri ${ }^{\mathrm{c}}$, Evelyne Willems ${ }^{\mathrm{a}}$, Unal Duran ${ }^{\mathrm{d}}$, \\ Ludovic Belle $^{\mathrm{a}}$, Frédéric Baron ${ }^{\mathrm{a}}$, Yves Beguin ${ }^{\mathrm{a}}$, Pierre Maquet ${ }^{\mathrm{b}}$, Olivier Bodart ${ }^{\mathrm{b}, 2}$, \\ Sophie Servais ${ }^{\mathrm{a}, *, 2}$
}

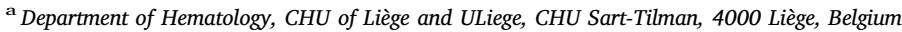

${ }^{\mathrm{b}}$ Department of Neurology, CHU of Liège and ULiege, CHU Sart-Tilman, 4000 Liège, Belgium

${ }^{c}$ Department of Clinical Biology, CHU of Liège and ULiege, CHU Sart-Tilman, 4000 Liège, Belgium

d Department of Radiology, CHU of Liège and ULiege, CHU Sart-Tilman, 4000 Liège, Belgium

\section{A R T I C L E I N F O}

\section{Keywords:}

Neuronal surface antibody-mediated

encephalopathy

Graft-versus-host disease

Allogeneic hematopoietic cell transplant

Central nervous system

PET-CT imaging

\begin{abstract}
A B S T R A C T
Although it remained controversial for a long time, central nervous system (CNS) involvement of graft-versushost disease (GVHD) is now becoming recognized as a real nosological entity. Previous case reports have suggested heterogeneous clinical presentations and it is not excluded that the whole spectrum of manifestations has not yet been fully described. Here, we report the case of a 58-year-old man with chronic GVHD who developed a rapidly ingravescent encephalopathy. There was no evidence for CNS immune-mediated lesions on conventional imaging nor for cellular infiltration in the cerebrospinal fluid. Serum analyses revealed the presence of antineuronal antibodies directed against anti-contactin-associated protein 2 (anti-Caspr2), a protein associated with voltage-gated potassium neuronal channels. Functional imaging with 2-deoxy-2-[fluorine-18] fluoro- D-glucose integrated with computed tomography (18F-FDG PET-CT) demonstrated diffuse cortical and subcortical hypometabolism. The patient was treated with a combination of immunosuppressive agents (corticosteroids, cyclophosphamide and rituximab) and progressively recovered normal neurocognitive functions. Taken together, these data suggest that CNS-GVHD may manifest as a reversible antibody-mediated functional encephalopathy. This report suggests for the first time the interest of screening for anti-neuronal antibodies and functional imaging with brain 18F-FDG PET-CT in diagnosing this severe complication of allogeneic hematopoietic cell transplantation (alloHSCT).
\end{abstract}

\section{Introduction}

Allogeneic hematopoietic stem cell transplantation (alloHSCT) offers curative treatment for a number of hematological malignancies (Appelbaum et al., 2004, Copelan, 2006, Gratwohl et al., 2010, Majhail et al., 2015,). However, its outcome can be compromised by the occurrence of graft-versus-host disease (GVHD), a complex pathologic process in which donor immune cells attack the recipient's healthy tissues (AbouMourad et al., 2010; Bhatia et al., 2007; Ferrara et al., 2009; Schmitz et al., 2006; Solomon et al., 2017). Common targets are the skin, gastrointestinal tract and liver, especially in the acute form of GVHD. Progression to chronic form may theoretically affect any organ and is characterized by clinical manifestations resembling those observed in autoimmune disorders (Jagasia et al., 2015, Pechey et al., 2015, Terada et al., 2017). Few cases of GVHD of the central nervous system (CNS-GVHD) have been reported so far (Ruggiu et al., 2017). However, it is not excluded that this complication is underdiagnosed (Armstrong et al., 1997; Rouah et al., 1988). Here, we report the case of a 58-year-old man with

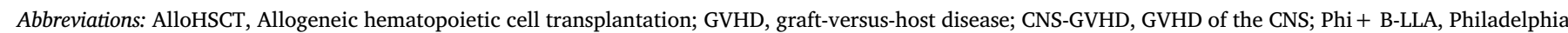

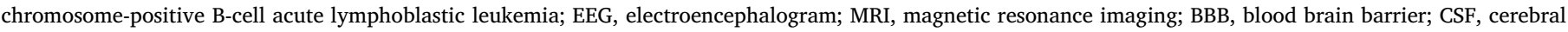
spinal fluid; Caspr2, contactin-associated protein 2; Cy, cyclophosphamide

* Correspondence author.

E-mail address: s.servais@chuliege.be (S. Servais).

${ }^{1} \mathrm{MP}$ and FF are co-first authors.

${ }^{2} \mathrm{OB}$ and SS are co-senior authors.
} 
probable CNS-GVHD manifesting as a severe neuronal surface antibodymediated encephalopathy.

\section{Case report}

The patient had a history of Philadelphia chromosome-positive Bcell acute lymphoblastic leukemia (Phi + B-LLA) for which he had undergone a non-myeloablative alloHSCT with peripheral blood stem cells from a 10/10 HLA-matched unrelated donor in January 2016. GVHD prophylaxis consisted of tacrolimus and rapamycin (in the context of a study protocol). Tacrolimus was stopped at month 6 and rapamycin at month 10 . The patient had also received maintenance therapy with imatinib for Phi + B-ALL and was in complete remission one year after alloHSCT.

At one year after alloHSCT, he presented with oral lichen planus and dry-eye symptoms with a pathological Schirmer test $(0$ and $3 \mathrm{~mm})$ and signs of keratoconjunctivitis sicca on corneal fluorescein staining examination. Topical therapies with dexamethasone mouthwashes and cyclosporine eye drops were initiated. A few weeks later, he developed pericardial effusion, without evidence of parainfectious or paraneoplastic etiology. Simultaneously, he started complaining of progressive asthenia, drowsiness, inattention, irritability, moderate transient headaches and weight loss. The clinical examination revealed bradypsychia, cognitive impairment, dyspraxia, ataxia, a pyramidal syndrome, and autonomic dysfunction with orthostatic hypotension and hyperhidrosis.

The electroencephalogram (EEG) showed diffuse moderate slowing of the dominant rhythm without paroxysmal activity. Screening tests for common metabolic or toxic causes of encephalopathy were negative. The brain magnetic resonance imaging (MRI) demonstrated only mild non-specific infra- and supratentorial leukoencephalopathy, that was stable in comparison with an MRI performed 1 year before. A lumbar puncture was performed and the cerebrospinal fluid (CSF) analyses revealed 5 leucocytes $/ \mu \mathrm{L}$, normal glycorrachia but hyperproteinorachia $(936 \mathrm{mg} / \mathrm{L})$ with elevated immunoglobulin $\mathrm{G}$ (IgG, $66 \mathrm{mg} /$ L) with an oligoclonal profile (isoelectric focusing). Reiber's graph did not suggest active intrathecal IgG secretion but rather an abnormal blood-brain barrier (BBB) permeation (IgG index of 6.8). Direct examination and microbiological cultures of the CSF were negative. Cryptococcal antigen was not detected and the panel PCR assay (including PCR for HSV-1 and -2, EBV, CMV, VZV, HHV6, enterovirus, parechovirus, BK/JC virus, toxoplasma and Listeria monocytogenes) returned negative. There was no evidence of leukemic cerebro-meningeal infiltration on cytology, immunophenotyping and molecular analyses. Serum analyses revealed a non-specific activation of the humoral immunity with an elevated titer of homogeneous antinuclear antibodies (dilution: 1/2560) with anti-nucleosome characterization $(52 \mathrm{U} / \mathrm{mL})$. Anti-neuronal antibodies were screened in the serum and antibodies directed against contactin associated protein like 2 (Caspr2, a protein associated with voltage-gated potassium neuronal channels) were found (immunofluorescent assay on transfected cells) (Fig. A1). A chest CT scan was performed and excluded a thymoma or a lung cancer.

Rapidly (within 10-14 days), neurological symptoms worsened, with progressive confusion, mutism, dizziness and fluctuations of consciousness. A 18F-FDG brain PET-CT demonstrated diffuse cortical and subcortical hypometabolism. Fifteen days after his admission, the patient presented a generalized epileptic seizure, followed by a profound alteration of consciousness (without argument for status epilepticus) and was transferred to the intensive care unit. A control brain MRI did not reveal any novel phenomenon. A second lumbar puncture was superimposable to the first one.

Based on the lack of evidence for any other cause, the context of oral and ocular cGVHD, seritis and biological signs of dysimmunity as well as the recent discontinuation of immunosuppressive drugs, we considered that the diagnosis of CNS-GVHD was probable and treatment with high dose corticosteroids was initiated (IV methylprednisolone $1 \mathrm{~g}$ /day for 5 days, standard to protocols for CNS autoimmune encephalitis), in addition to supportive care and antiepileptic therapy with levetiracetam. The patient rapidly recovered consciousness and returned back to the conventional care unit. We decided to continue maintenance therapy with $1 \mathrm{mg} / \mathrm{kg}$ /day oral methylprednisolone in combination with IV boluses of cyclophosphamide (Cy, $500 \mathrm{mg} / \mathrm{m}^{2}$ every 3 weeks). Given the biological signs of humoral immunity activation with anti-neuronal antibodies, we added rituximab $\left(375 \mathrm{mg} / \mathrm{m}^{2}\right.$ once a week, for 4 administrations).

Neurocognitive functions recovered progressively over a few months. No epileptic seizure recurred. The treatment also enabled improvement of GVHD mouth and ocular symptoms as well as complete regression of the pericardial effusion. At six months, control EEG and brain PET-CT showed normalization of the cerebral electrical activity and cortical metabolism, respectively. From that moment on, the patient had recovered completely normal neurocognitive functions. At month 10, anti-Caspr2 antibodies were negative. Considering this favorable evolution, dosage of corticosteroids was gradually tapered after three months of their introduction (approximately $20 \%$ of dose reduction every 1-2 weeks during two months) to reach a dose of $8 \mathrm{mg} /$ day at 5 months. This dose was maintained over 5 additional months, and corticosteroid therapy was definitively stopped by 10 months after its initiation. Cy was maintained up to 13 months, when it was discontinued. The patient did not experience any recurrence of abnormal neurological signs. Periodical brain PET-CT and anti-neuronal antibody screening are planned for the patient's follow-up in the coming years.

\section{Discussion}

Historically, it was considered that the CNS could not be affected by GVHD. However, over the last decade, preclinical data (Belle et al., 2017; Hartrampf et al., 2013; Sostak et al., 2004) and clinical case reports (Harvey et al., 2014; Openshaw et al., 1995; Sostak et al., 2010; Stefanou and Bischof, 2017; Voss and Bischof, 2010) progressively accumulated and CNS-GVHD is now becoming recognized as a true entity (Armstrong et al., 1997; Belle et al., 2017; Grauer et al., 2010; Hartrampf et al., 2013; Harvey et al., 2014; Maffini et al., 2017; Openshaw et al., 1995; Rouah et al., 1988; Ruggiu et al., 2017; Sostak et al., 2004; Sostak et al., 2010; Stefanou and Bischof, 2017; Voss and Bischof, 2010). Nevertheless, the diagnosis of CNS-GVHD still remains difficult mainly because of the low prevalence of the disease, confounding factors and heterogeneous clinical presentations. Moreover, the whole clinical spectrum of the entity has not yet been fully described. Previous reports have suggested that CNS-GVHD can present with three main clinico-pathological manifestations: immune-mediated vasculitis, immune-mediated demyelinating lesions and immunemediated encephalitis (Campbell and Morris, 2005; Delios et al., 2012; Grauer et al., 2010; Harvey et al., 2014; Maffini et al., 2017; Padovan et al., 1999; Ruggiu et al., 2017; Saad et al., 2009; Tomonari et al., 2003). Here, we report a case of CNS-GVHD presenting as an ingravescent encephalopathy, without any significant lesion on MRI but with diffuse alteration of brain activity on 18F-FDG PET-CT imaging. Serum analyses revealed the presence of anti-neuronal antibodies directed towards a protein associated with voltage-gated potassium neuronal channels. Neurocognitive functions completely recovered and 18F-FDG PET-CT imaging normalized after immunosuppressive therapy. Taken together, these data suggest that CNS-GVHD could also manifest as a reversible immune-mediated encephalopathy.

In 2009, Openshaw described six diagnostic criteria for CNS-GVHD, including: (1) chronic GVHD affecting other organs, (2) neurological signs of CNS involvement without other explanation, (3) abnormal CSF studies (pleocytosis, elevated protein or immunoglobulin G, oligoclonal bands), (4) brain MRI abnormality, (5) pathological brain biopsy or post-mortem examination and (6) response to immunosuppressive therapy (Openshaw, 2009). Initially, all of those six criteria were considered mandatory to make the definite diagnosis of CNS-GVHD. However, in a report from the Consensus Conference on Clinical Practice in chronic graft-versus-host disease (Grauer et al., 2010), Grauer 
et al. proposed more flexibility and suggested that the diagnosis of 'possible' CNS-GVHD could also be made when the first two criteria and at least two of the 4 remaining criteria were met, considering that pathological findings on brain MRI, CSF studies or brain histology could be facultative, as well as response to treatment (Grauer et al., 2010). In our case, four criteria were met. Interestingly, brain MRI did not reveal any significant parenchymal lesions. We did not attempt to perform a brain biopsy, both because of the lack of specific MRI abnormalities for guiding relevant biopsy and because of rapid clinical deterioration prompting initiation of empirical immunosuppressive therapy.

In our case, 18F-FDG brain PET-CT demonstrated diffuse cortical and subcortical hypometabolism that completely normalized following immunosuppressive therapy. Functional imaging with 18F-FDG brain PET-CT recently emerged as a useful tool for improving the diagnosis of some auto-immune encephalitis (Celliers et al., 2016; Dong et al., 2016; Lagarde and Guedj, 2015; Morbelli et al., 2017). Whether it could also bring relevant complementary information to integrate in the diagnostic algorithm of CNS-GVHD, especially in patients with normal MRI, is not known and has to be explored in the future.

Serum analyses from our patient revealed the presence of antineuronal antibodies directed against Caspr2, a protein associated with voltage-gated potassium neurological channels. The clinical spectrum of anti-Caspr2 antibody-associated autoimmune disease is still not well established. Most patients have symptoms originating from multiple areas of the nervous system (e.g. limbic encephalitis, Morvan's syndrome, neuromyotonia ...). By studying one of the largest series of 38 patients with anti-Caspr2 auto-antibodies, Van Sonderen et al. recently reported that the resulting syndrome might indeed be diverse, including a set of symptoms such as cognitive deficits, epilepsy, insomnia, cerebellar dysfunction, autonomic dysfunction, peripheral nerve hyperexcitability, neuropathic pain, and weight loss (Van Sonderen et al., 2016). Our patient presented with several of these symptoms.

The Reiber's graph on CSF was not evocative of an active intrathecal secretion of IgG, but rather suggested a passive transfer of peripheral antibodies through the inflamed BBB. Search for antineuronal antibody in the serum and in the CSF is theoretically the best approach for diagnosing encephalitis (Grauss et al., 2016). Unfortunately, anti-Caspr2 antibodies were not screened in the CSF of our patient because of practical limitation in our institution. However, the detection of anti-
Caspr2 antibodies in the serum, the compatible clinical presentation, the abnormal neuronal activity on brain PET-CT as well as the rapid clinical improvement under immunosuppressive therapy support the diagnosis of immune-mediated encephalopathy in our patient. Association between anti-Caspr2 antibodies and solid malignancies have been reported in some cases (Popławska-Domaszewicz et al., 2018). Here, the presence of other signs of cGVHD, the normal chest CT-scan and the favorable clinical evolution (good general well-being at more than one year of follow-up) can reasonably rule out the hypothesis of a paraneoplastic syndrome in our patient.

To the best of our knowledge, this is the first case report of CNS-GVHD with evidence of humoral dysimmunity. Previous clinical reports mainly mentioned T-cell mediated CNS lesions or encephalitis (Iwasaki et al., 1993; Kamble et al., 2007; Marosi et al., 1990; Saad et al., 2009). However, it is now recognized that B cells play an important role in the pathophysiology of systemic chronic GVHD (MacDonald et al., 2017; Rhoades and Gaballa, 2017). Considering biological signs of B-cell activation in our patient, we added anti-B cell treatment with rituximab (an anti-CD20 antibody) to corticosteroid-cyclophosphamide combination therapy. Efficacy of rituximab for the treatment of chronic GVHD has been proven in several studies (Brownback et al., 2017; Wolff et al., 2011).

The patient progressively recovered normal neurocognitive functions and PET-CT imaging normalized under immunosuppressive therapy, suggesting the reversible course of the disease under treatment.

\section{Conclusion}

CNS-GVHD should be included in the differential diagnosis of encephalopathy in patients after alloHSCT, particularly if they present signs of GVHD in other organs. A rapid work-up is essential to promptly initiate appropriate immunosuppressive treatment. Screening for antineuronal antibodies and the use of functional imaging with brain 18FFDG PET-CT should be considered as additional tools to help the diagnosis. In such difficult cases, close collaboration between neurologists and hematologists is essential for the management of patients.

\section{Declarations of interest}

None.

\section{Appendix A}

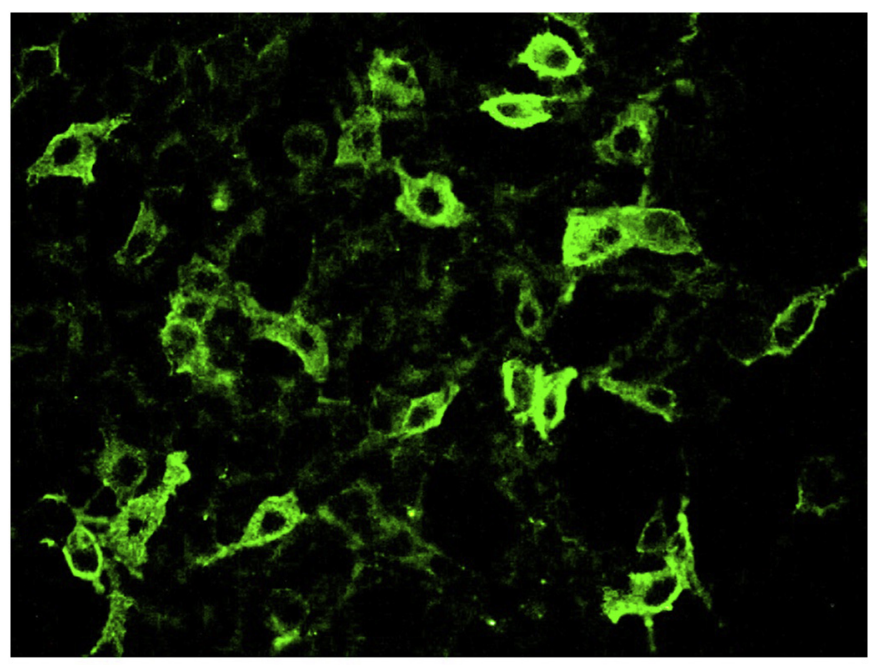

Immunofluorescent assay on transfected cells: Image of anti-CASPR2 obtained using

the transfected cell method with patient blood sample

Fig. A1. 


\section{References}

Abou-Mourad, Y.R., Lau, B.C., Barnett, M.J., et al., 2010. Long-term outcome after alloSCT: close follow-up on a large cohort treated with myeloablative regimens. Bone Marrow Transplant. 45 (2), 295-302. https://doi.org/10.1038/bmt.2009.128.

Appelbaum, F.R., Forman, S.J., Blume, K.G., Negrin, R.S., 2004. Hematopoietic Cell Transplantation for Acquired Diseases. Thomas' Hematopoietic Cell Transplantation, 4th edition. Wiley-Blackwell, USA, pp. 707-985.

Armstrong, D., Hawkins, E., Rouah, E., et al., 1997. Graft-vs-host disease in the central nervous system. Am. J. Clin. Pathol. 107 (3), 379.

Belle, L., Zhou, V., Stuhr, K.L., Beatka, M., Siebers, E.M., Knight, J.M., Drobyski, W.R., 2017. Host interleukin 6 production regulates inflammation but not tryptophan metabolism in the brain during murine GVHD. JCI Insight 2 (14). https://doi.org/10. 1172/jci.insight.93726.

Bhatia, S., Francisco, L., Carter, A., et al., 2007. Late mortality after allogeneic hematopoietic cell transplantation and functional status of long-term survivors: report from the Bone Marrow Transplant Survivor Study. Blood 110 (10), 3784-3792. https:// doi.org/10.1182/blood-2007-03-082933.

Brownback, K.R., Thomas, L.A., McGuirk, J.P., Ganguly, S., Streiler, C., Abhyankar, S., 2017. Effect of rituximab on pulmonary function in bronchiolitis obliterans syndrome due to graft-versus-host-disease. Lung 195 (6), 781-788. https://doi.org/10.1007/ s00408-017-0051-0.

Campbell, J.N., Morris, P.P., 2005. Cerebral vasculitis in graft-versus host disease: a case report. Am. J. Neuroradiol. 26 (3), 654-656.

Celliers, L., Hung, T., Al-Ogaili, Z., Moschilla, G., Knezevic, W., 2016. Voltage-gated potassium channel antibody limbic encephalitis: a case illustrating the neuropsychiatric and PET/CT features with clinical and imaging follow-up. Austr. Psychiatry 24 (6), 538-540. https://doi.org/10.1177/1039856216663734.

Copelan, E.A., 2006. Hematopoietic stem-cell transplantation. N. Engl. J. Med. 354 (17), 1813-1826. https://doi.org/10.1056/NEJMra052638.

Delios, A.M., Rosenblum, M., Jakubowski, A.A., et al., 2012. Central and peripheral nervous system immune mediated demyelinating disease after allogeneic hematopoietic stem cell transplantation for hematologic disease. J. Neuro. Oncol. 110 (2), 251-256. https://doi.org/10.1007/s11060-012-0962-9.

Dong, A., Gao, M., Wang, Y., Gao, L., Zuo, C., 2016. Interesting image FDG PET / CT in acute tumefactive multiple sclerosis occurring in a case of chronic graft-versus-host disease after allogeneic hematopoietic stem cell transplantation. Clin. Nucl. Med. 41 (9), e414-e416. https://doi.org/10.1097/RLU.0000000000001193.

Ferrara, J., Levine, J., Reddy, P., Holler, E., 2009. Graft-versus-host disease. Lancet 373 (9674), 1550-1561. https://doi.org/10.1016/S0140-6736(09)60237-3.

Gratwohl, A., Baldomero, H., Aljurf, M., Pasquini, M.C., Bouzas, L.F., Yoshimi, A., et al., 2010. Hematopoietic stem cell transplantation: a 360 globales perspectives. JAMA 303 (16), 1617-1624. 25. https://doi.org/10.1001/jama.2010.491.

Grauer, O., Wolff, D., Bertz, H., et al., 2010. Neurological manifestations of chronic graftversus-host disease after allogeneic hematopoietic stem cell transplantation: report from the consensus conference on clinical practice in chronic graft-versus-host disease. Brain 133 (10), 2852-2865. https://doi.org/10.1093/brain/awq245.

Grauss, Francesc, Titulaer, Maarten J., Balu, Ramani, Benseler, Susanne, et al., 2016. A clinical approach to diagnosis of autoimmune encephalitis. Lancet Neurol. 15 391-404. https://doi.org/10.1016/ S1474-4422(15)00401-9.

Hartrampf, S., Dudakov, J.A., Johnson, L.K., Smith, O.M., Tsai, J., Singer, N., et al., 2013. The central nervous system is a target of acute graft versus host disease in mice. Blood 121 (10), 1906-1910. https://doi.org/10.1182/blood-2012-09-456590.

Harvey, C.M., Gottipati, R., Schwarz, S., et al., 2014. Acute disseminated encephalomyelitis following allo-SCT: central nervous system manifestation of GVHD. Bone Marrow Transplant. 49 (6), 854-856. https://doi.org/10.1038/bmt.2014.29.

Iwasaki, Y., Sako, K., Ohara, Y., et al., 1993. Subacute panencephalitis associated with chronic graft-versus-host disease. Acta Neuropathol. 85 (5), 566-572. https://doi. org /10.1007/BF00230498.

Jagasia, M.H., Greinix, H.T., Arora, M., et al., 2015. National Institutes of Health consensus development project on criteria for clinical trials in chronic graft-versus-host disease: I. The 2014 diagnosis and staging working group report. Biol. Blood Marrow Transpl. 21 (3), 389-401. https://doi.org/10.1016/j.bbmt.2014.12.001.

Kamble, R.T., Chang, C.C., Sanchez, S., et al., 2007. Central nervous system graft versushost disease: report of two cases and literature review. Bone Marrow Transplant. 39 (1), 49-52. https://doi.org/10.1038/sj.bmt.1705540.

Lagarde, S., Guedj, E., 2015. Interest of cerebral positron emission tomography (PET) in dysimmune encephalitis. Med. Nucl. 39 (3), 279-282. https://doi.org/10.1016/j mednuc.2015.03.002

MacDonald, K.P.A., Hill, G.R., Blazar, B.R., 2017. Chronic graft-versus-host disease: biological insights from preclinical and clinical studies. Blood 129 (1), 13-21. https://doi.org/10.1182/blood-2016-06-686618.

Maffini, E., Festuccia, M., Brunello, L., Boccadoro, M., Giaccone, L., Bruno, B., 2017. Neurologic complications after allogeneic hematopoietic stem cell transplantation. Biol. Blood Marrow Transplant. 23 (3), 388-397. https://doi.org/10.1016/j.bbmt.
2016.12.632.

Majhail, N.S., Farnia, S.H., Carpenter, P.A., Champlin, R.E., Crawford, S., Marks, D.I., Palmer, J., 2015. Indications for autologous and allogeneic hematopoietic cell transplantation: guidelines from the American Society for Blood and Marrow Transplantation. Biol. Blood Marrow Transplant. 21 (11), 1863-1869. https://doi. org/10.1016/j.bbmt.2015.07.032.

Marosi, C., Budka, H., Grimm, G., et al., 1990. Fatal encephalitis in a patient with chronic graft-versus-host disease. Bone Marrow Transplant. 6 (1), 53-57.

Morbelli, S., Arbizu, J., Booij, J., Chen, M.K., Chetelat, G., Cross, D.J., Barthel, H., 2017. The need of standardization and of large clinical studies in an emerging indication of [18F] FDG PET: the autoimmune encephalitis. Eur. J. Nucl. Med. Mol. Imaging 44 (3), 353-357. https://doi.org/10.1007/s00259-016-3598-8.

Openshaw, H., 2009. Neurological Manifestations of Chronic Graft Versus Host Disease. Chronic Graft versus Host Disease. Cambridge University Press, New York, pp. 243-255.

Openshaw, H., Slatkin, N.E., Parker, P.M., Forman, S.J., 1995. Immune mediated myelopathy after allogeneic marrow transplantation. Bone Marrow Transplant. 15 (4), 633-636.

Padovan, C.S., Bise, K., Hahn, J., et al., 1999. Angiitis of the central nervous system after allogeneic bone marrow transplantation? Stroke J. Cereb. Circ. 30 (8), 1651-1656. https://doi.org/10.1038/bmt.2009.323.

Pechey, V., Parratt, J., Vo, L., Stevenson, W., 2015. Successful treatment of meningea graft-versus-host disease in a hematopoietic stem cell transplant recipient. Int. J. Hematol. 101 (2), 203-206. https://doi.org/10.1007/s12185-014-1704-x.

Popławska-Domaszewicz K., Florczak-Wyspiańska J., Kozubski W. and Michalak S., 2018. Paraneoplastic movement disorders. Rev. Neurosci. 0(0), 1-11. :https://doi.org/10. 1515/revneuro-2017-0081.

Rhoades, R., Gaballa, S., 2017. The role of B cell targeting in chronic graft-versus-host disease. Biomedicine 5 (4), E61. https://doi.org/10.3390/biomedicines5040061.

Rouah, E., Gruber, R., Shearer, W., et al., 1988. Graft-versus-host disease in the central nervous system: a real entity? Am. J. Clin. Pathol. 89 (4), 543-546.

Ruggiu, M., Cuccuini, W., Mokhtari, K., Meignin, V., Peffault De Latour, R., Robin, M., Michonneau, D., 2017. Case report: central nervous system involvement of human graft versus host disease. Medicine 96 (42), e8303. https://doi.org/10.1097/MD. 0000000000008303

Saad, A.G., Alyea, E.P., Wen, P.Y., et al., 2009. Graft-versus-host disease of the CNS after allogeneic bone marrow transplantation. J. Clin. Oncol. 27 (30), e147-e149. https:// doi.org/10.1200/JCO.2009.21.7919.

Schmitz, N., Eapen, M., Horowitz, M.M., et al., 2006. Long-term outcome of patients given transplants of mobilized blood or bone marrow: a report from the International Bone Marrow Transplant Registry and the European Group for Blood and Marrow Transplantation. Blood 108 (13), 4288-4290. https://doi.org/10.1182/blood-200605-024042.

Solomon, S.R., Sizemore, C., Zhang, X., et al., 2017. Current GVHD-free, relapse-free survival - a dynamic endpoint to better define efficacy following allogenic transplant. Biol. Blood Marrow Transplt. 23 (7), 1208-1214. https://doi.org/10.1016/j.bbmt. 2017.02.022.

Sonderen, A., Van Ariño, H., Petit-Pedrol, M., Leypoldt, F., Körtvélyessy, P., Lancaster, E., Schreurs, M.W.J., 2016. The clinical spectrum of Caspr2 antibody - associated disease. Neurology 87 (5), 521-528. https://doi.org/10.1212/WNL. 0000000000002917.

Sostak, P., Reich, P., Padovan, C.S., Gerbitz, A., Holler, E., Straube, A., 2004. Cerebral endothelial expression of adhesion molecules in mice with chronic graft-versus-host disease. Stroke 35 (5), 1158-1163. https://doi.org/10.1161/01.STR.0000125865. 01546.bb.

Sostak, P., Padovan, C.S., Eigenbrod, S., Roeber, S., Segerer, S., Schankin, C., et al., 2010. Cerebral angiitis in four patients with chronic GVHD. Bone Marrow Transplant. 45 (7), 1181-1188. https://doi.org/10.1038/bmt.2009.323.

Stefanou, M.I., Bischof, F., 2017. Central and peripheral nervous system immune-mediated demyelinating disease after allogeneic hematopoietic stem cell transplantation. J. Neuroimmunol. 307, 74-81. https://doi.org/10.1016/j.jneuroim.2017.04.005.

Terada, M., Nakamagoe, K., Obara, N., Ogawa, S., Sakamoto, N., Sato, T., et al., 2017. Chronic graft-versus-host disease presenting with multiple punctate intracranial lesions on contrast-enhanced magnetic resonance imaging. Intern. Med. 56 (3), 363-368. https://doi.org/10.2169/internalmedicine.56.7329.

Tomonari, A., Tojo, A., Adachi, D., et al., 2003. Acute disseminated encephalomyelitis (ADEM) after allogeneic bone marrow transplantation for acute myeloid leukemia. Ann. Hematol. 82 (1), 37-40. https://doi.org/10.1007/s00277-002-0573-1.

Voss, M., Bischof, F., 2010. Recurrent myelitis after allogeneic stem cell transplantation. Report of two cases. BMC Neurol. 10, 76. https://doi.org/10.1186/1471-2377-10-76.

Wolff, D., Schleuning, M., Von Harsdorf, S., Bacher, U., Gerbitz, A., Stadler, M., Holler, E., 2011. Consensus conference on clinical practice in chronic GVHD: second-line treatment of chronic graft-versus-host disease. Biol. Blood Marrow Transpl. 17 (1), 1-17. https://doi.org/10.1016/j.bbmt.2010.05.011. 